\title{
Limites à regulação, conforme o Poder Judiciário ${ }^{1}$
}

\author{
João Batista Gomes Moreira \\ Mestre e Doutor em Direito Administrativo pela Universidade Federal de Minas Gerais. \\ Desembargador Federal do Tribunal Regional Federal da 1a Região.
}

\begin{abstract}
Resumo: A regulação consiste na promoção processual do equilíbrio entre interesses políticos, interesses dos agentes econômicos e prestadores de serviços públicos, interesses de consumidores ou usuários de bens e serviços e até interesses de pessoas atingidas em suas propriedades. Traçar os limites à regulação, conforme o Poder Judiciário, nesses três campos, é o objeto desta exposição. Examinam-se alguns casos relativos à regulação normativa e à regulação julgadora. A regulação normativa bifurca-se em dois itens: a) regulamentação executiva de texto legal; b) regulamentação autônoma ou sem intermediação legal. Conquanto possa a administração complementar a norma penal em branco, não tem, conforme a jurisprudência, competência para tipificar infrações e estabelecer respectivas sanções, mesmo administrativas, ou criar tributos. A regulação autônoma está submetida aos requisitos de necessidade e relevância, não pode invadir campo especificamente reservado à lei formal, mesmo na ausência desta, e não subsiste uma vez editada lei sobre a matéria. Ensaia-se na jurisprudência discussão sobre limite negativo à regulação julgadora.
\end{abstract}

Palavras-chave: Limite. Regulação. Normativa. Julgadora.

Sumário: 1 Limites à regulação normativa - 2 Limites à regulação julgadora

Falar sobre os limites à regulação pressupõe, obviamente, saber o que seja regulação e o conhecimento dessa espécie de atividade estatal implica situá-la no conjunto de atividades do poder público.

Sabe-se que no Estado absolutista o soberano concentrava, sem distinção, as três clássicas funções estatais - legislação, administração e jurisdição.

$\mathrm{Na}$ evolução para o Estado de Direito, foram paulatinamente retiradas da competência do rei e atribuídas a órgãos independentes a legislação - atribuição de criar normas gerais e abstratas — e a jurisdição atividade consistente em solucionar, concretamente, conflitos individuais.

O que permaneceu na esfera do poder real é o que constitui, no Estado de Direito, a atividade tipicamente administrativa. O critério residual é o mais utilizado para chegar-se, se não a um conceito, à noção de função administrativa.

\footnotetext{
Texto básico de palestra proferida em Uberlândia, 5.8.2010, no Seminário de Direito Administrativo do Triângulo Mineiro, promovido pelo Instituto de Direito Administrativo de Minas Gerais.
} 
A essa noção deve acrescentar-se que legislação e jurisdição, na verdade, são apenas o produto, resultado essencial, das funções legislativa e jurisdicional, pois as atividades-meio das funções legislativa e jurisdicional também ostentam natureza administrativa.

Nessa perspectiva, pode-se concluir que são administrativas as atividades-meio das três funções básicas do Estado e, além disso, são administrativas no pleno sentido da designação, as atividades-fim da função executiva, com exceção aqui, apenas, das atividades políticas ou de governo.

Nesse contexto, onde se situa a regulação?

Pelo menos do ponto de vista estrutural, a regulação é uma das atividades-fim da função executiva, às vezes guardando a mesma natureza, mas destacada das tradicionais atividades administrativas (intervenção executiva do Estado na propriedade e no domínio econômico e social, polícia administrativa e serviço público).

A regulação, fugindo à perspectiva dos atos autoritários da administração clássica, consiste na promoção processual do equilíbrio entre interesses políticos, interesses dos agentes econômicos e prestadores de serviços públicos, interesses de consumidores ou usuários de bens e serviços e até interesses, por exemplo, de pessoas atingidas em suas propriedades - como acaba de expor o professor Alexandre Aragão -, pela construção de estruturas ferroviárias. Na promoção desse equilíbrio, a entidade estatal competente desenvolve atividade normativa, atividade administrativa propriamente dita e atividade decisória de conflitos.

Traçar os limites à regulação, conforme o Poder Judiciário, nesses três campos, é o objeto desta exposição. Deve-se buscar, pois, subsídios na jurisprudência, o que se fará mediante exame de alguns casos relativos à regulação normativa e à regulação julgadora, assentando que na regulação propriamente administrativa não há peculiaridade relevante, do ponto de vista jurisprudencial, nas atividades das agências reguladoras, a não ser, talvez, em relação ao exercício da discricionariedade técnica, que predomina nessas entidades.

\section{Limites à regulação normativa}

A regulação normativa bifurca-se em dois itens: a) regulamentação executiva de texto legal; b) regulamentação autônoma ou sem intermediação legal. 
Quanto à regulamentação executiva, há quem entenda ser competência privativa do Presidente da República (art. 84, IV, da Constituição) e que, apesar de, tecnicamente, ser delegável toda competência privativa, como há a regra do parágrafo único, especificando competências delegáveis, não haveria, a contrario sensu, outras possibilidades de delegação. Em posição contrária, sustenta-se que: a) a regra do art. 84, parágrafo único, deve ser interpretada como indicação dos destinatários das delegações ali mencionadas, pois toda competência privativa é, por natureza, delegável; b) não está e nem poderia estar excluída a atividade interpretativa das leis, inclusive em caráter abstrato, pelos demais órgãos e entidades da administração encarregados de aplicá-las, aos quais as próprias leis (chamadas leis-quadro) muitas vezes transferem essa atribuição, de forma expressa ou implícita, neste caso ao referir-se, genericamente, a valores morais, políticos e econômicos ou ao empregar conceitos flexíveis, porosos, tópicos e programáticos (indeterminados); c) da disposição do art. 84, IV, deve ser excluída a regulação setorial de matérias técnicas, em constante transformação, cujo tratamento é atribuição natural de entidades e órgãos especializados; d) a própria Constituição excepciona a regra do art. 84, IV, ao prever a criação de agências reguladoras, com competência normativa.

Nessa seara, traduzindo a segunda posição, há acórdão que, bem a propósito, versa sobre matéria submetida ao princípio da legalidade estrita. Resultou de julgamento, pelo Supremo Tribunal Federal, em 20.03.2003, do RE no 343446/SC, relator Ministro Carlos Velloso, afirmando-se que "o fato de a lei deixar para o regulamento a complementação dos conceitos de 'atividade preponderante' e 'grau de risco leve, médio e grave', não implica ofensa ao princípio da legalidade genérica, C. F., art. 50, II, e da legalidade tributária, C. F., art. 150, I". Este expositor, quando ainda na primeira instância julgava a questão, costumava lembrar que a própria lei penal, em que vigoram por excelência os princípios da legalidade estrita e da tipicidade fechada, admite a técnica da norma penal em branco.

É oportuno ressalvar que, conquanto possa a administração complementar a norma penal em branco, não tem, conforme a jurisprudência, competência para tipificar infrações e estabelecer respectivas sanções, mesmo administrativas, ou criar tributos, matéria que está reservada à lei formal. Trata-se de orientação que já levou os tribunais a 
anular sanções aplicadas pelo Instituto Brasileiro do Meio Ambiente com base em instrução normativa, conforme as seguintes decisões:

ADMINISTRATIVO. IBAMA. INFRAÇÃO. APLICAÇÃO DE MULTA. CONTRAVENÇÃO PENAL.

Se o ato originário do auto de infração é tipificado como contravenção penal, é vedado ao funcionário do IBAMA a aplicação de multa, visto que não se trata de infração administrativa.

Só a lei, em sentido formal e material, pode tipificar infração e impor penalidade.

Recurso improvido.

(STJ, 1a Turma, REsp no 117.847/MG. Relator: Ministro José Delgado. Data do julgamento: 17.06.1997, DJ, 18 ago. 1997, p. 37.789)

ADMINISTRATIVO. IBAMA. INFRAÇÃO. PRINCÍPIO DA LEGALIDADE. CONTRAVENÇÃO.

A delegação de competência prevista no Decreto-Lei n. 289/67 perdeu a eficácia jurídica com a edição da Emenda Constitucional n. 11/78 (art. $3^{\circ}$ ), não tendo sido recepcionada pelo art. 25 do ADCT da Constituição de 1988.

A Portaria n. 267/88-IBDF viola o princípio da reserva legal, por isso que somente a lei pode descrever infração e impor penalidade.

A aplicação de multa decorrente de contravenção penal cabe ao poder judiciário.

Apelação improvida.

(TRF, $1^{\text {a }}$ Região, 4a Turma, 94.01.08999-8/GO. Relator: Desembargador Federal Mário César Ribeiro. Data de julgamento: 17.06.1996, DJ, 22 ago.1996, p. 59.870)

ADMINISTRATIVO E TRIBUTÁRIO. TAXA DE POLÍCIA E INFRAÇÃO ADMINISTRATIVA. PRINCÍPIO DA ESTRITA LEGALIDADE. INSTITUIÇÃO EM SIMPLES PORTARIA DO IBAMA. AFASTAMENTO DA EXAÇÃO E NULIDADE DO AUTO DE INFRAÇÃO.

Se o processo envolve matérias conexas da competência de distintas Seções do Tribunal, firma-se a competência em função do interesse predominante, no caso, o interesse ambiental, que constitui a matéria subjacente.

O mandado de segurança é ação inadequada para se obter declaração de que o IBAMA é entidade incompetente para exercer a polícia florestal no Estado de Goiás.

Tem natureza tributária (taxa de polícia) a exação que o IBAMA pretendeu instituir, por simples portaria, para o deferimento de autorização de queima controlada, logo, sujeita ao princípio da legalidade.

A atividade punitiva da Administração, fora dos casos de autotutela, é uma excepcionalidade (resquício do Estado absolutista) que deve ser reduzida ao mínimo indispensável e cercada de garantias eficazes aos direitos do cidadão. 
Desatende, também, ao princípio da legalidade a instituição de pena de multa administrativa por simples portaria.

(TRF, 1a Região, 5a Turma, AMS n 2000.01.00.048772-0/GO. Relator: Desembargador Federal João Batista Gomes Moreira. Unânime. Data do julgamento: 04.03.2002. DJ, 15 maio 2002, p. 122)

Passo ao exame da regulamentação autônoma (regulamentação sem a intermediação de lei stricto sensu).

Já escrevi² que, na dicção de Miguel Reale, "governar é criar continuamente, é apreciar o imprevisto e decidir diante dos fatos que a lei não previu ou previu de maneira insuficiente".3 Se a Constituição dá os fins, implicitamente oferece os meios, segundo o princípio dos poderes implícitos, concebido por Marshall. ${ }^{4}$ Os poderes estatais, incluído o Executivo, "estão vinculados diretamente aos direitos fundamentais, que são considerados direitos diretamente aplicáveis" e princípios constitucionais podem ser razões para decisões concretas. ${ }^{5}$ Os preceitos constitucionais fundamentais, incluídos os relativos aos direitos fundamentais sociais, têm eficácia direta e imediata. ${ }^{6}$ E se a administração pode praticar atos concretos com fundamento em princípios e regras constitucionais, poderá estabelecer, mediante participação da sociedade e motivadamente, critérios gerais de ação, nisto consistindo uma espécie de regulamento autônomo. Pergunta Alexandre Santos de Aragão: "por que haveria poder para regulamentar leis ordinárias e não a própria lei constitucional?"7 Não se trata, como pode ser visto, de competência delegada pelo Poder Legislativo, mas de um poder próprio, derivado diretamente da Constituição.

A competência normativa autônoma do Poder Executivo é, ademais, apontada como uma necessidade prática do Estado contemporâneo, em face da complexidade, urgência e tecnicidade das matérias postas a cargo da administração. Cogita-se da divisão da função normativa em dois setores: à lei seria atribuída a finalidade de disciplinar a ordem geral e

2 Cf. MOREIRA, João Batista Gomes. Direito administrativo: da rigidez autoritária à flexibilidade democrática. 2. ed. Belo Horizonte: Fórum, 2010. p. 401 et seq.

3 REALE, Miguel apud DINAMARCO, Cândido Rangel. A instrumentalidade do processo. 9. ed. São Paulo: Malheiros, 2001. p. 41.

4 ARAGÃO, Alexandre Santos. Princípio da legalidade e poder regulamentar no Estado contemporâneo. Revista de Direito Administrativo, Rio de Janeiro, p. 124, 2001.

5 ALEXY, Robert. Teoria dos direitos fundamentais. Trad. Virgílio Afonso da Silva. São Paulo: Malheiros, 2008. p. $68,107$.

6 FREITAS, Juarez. A Interpretação sistemática do direito. 3. ed. rev. e ampl. São Paulo: Malheiros, 2002. p. 172, $183,210$.

ARAGÃO, op. cit., p. 124. 
abstrata, com vocação de permanência, criando-se um outro instrumento para a promoção do desenvolvimento econômico e social, a cargo do Poder Executivo, hoje objeto das chamadas leis de medida. De acordo com Bernard Schwartz, "a aplicação de uma concepção rígida da separação dos poderes tornaria impossível o Governo moderno".8 Não é por outra razão que o poder normativo autônomo da administração está consagrado em países como França, Itália, Alemanha, Inglaterra e Estados Unidos.

No Brasil, na medida em que a administração está, pela própria Constituição (e pela lei de improbidade administrativa), vinculada diretamente a outros princípios que não só o da legalidade, parece não ser pela ausência de lei formal (omissão em satisfazer o direito a "prestação normativa", para utilizar expressão de Robert Alexy), salvo reserva constitucional, que deixará de realizar as competências que Ihe são próprias e, se pode praticar atos individuais nesse caso, aplicando diretamente a Constituição, é natural que possa estabelecer critérios gerais de ação (norma). De acordo com a doutrina, como o procedimento regulamentar admite participação ampla dos cidadãos, democratiza o funcionamento da administração; concretiza os termos da lei de forma mais geral e menos arbitrária (casuística); permite o desenvolvimento de políticas públicas numa perspectiva global, valorando todos os aspectos envolvidos, o que implica sua maior eficácia; reduz a discricionariedade; facilita o controle. ${ }^{9}$

Em que pese divergências doutrinárias, a atividade normativa autônoma tem sido exercida ao longo de décadas por entidades como o Conselho Monetário Nacional, o Banco Central, a Secretaria da Receita Federal e o Conselho Nacional do Meio Ambiente. Do órgão ultimamente citado é bastante característica a Resolução no 237/97, cujo art. $6^{\circ}$ estabelece que "compete ao órgão ambiental municipal, ouvidos os órgãos competentes da União, dos Estados e do Distrito Federal, quando couber, o licenciamento de empreendimentos e atividades de impacto ambiental local e daquelas que Ihe forem delegadas pelo Estado por instrumento legal ou convênio".

De acordo com o art. 23 da Constituição, é competência (material) comum da União, dos Estados, do Distrito Federal e dos Municípios,

\footnotetext{
SCHWARTZ, Bernard apud CUÉLLAR, Leila. As agências reguladoras e seu poder normativo. São Paulo: Dialética, 2001. p. 115.

9 CARBONELL, Eloísa; MUGA, José Luis. Agencias y Procedimiento Administrativo en Estados Unidos de America. Madrid: Marcial Pons, 1996. p. 60.
} 
entre outras, proteger o meio ambiente e combater a poluição. Diz o parágrafo primeiro que "leis complementares fixarão normas para a cooperação entre a União e os Estados, o Distrito Federal e os Municípios, tendo em vista o equilíbrio do desenvolvimento e do bem-estar em âmbito nacional". Ocorre que ainda não há lei complementar destinada a tratar, especificamente, da referida competência comum. Aplica-se a Lei no 6.938/81, que se pode considerar recepcionada pela Constituição de 1988 como lei complementar. Entretanto, essa lei não prevê competência do Município para cuidar do meio ambiente.

A referida resolução do CONAMA, à evidência, é norma instituída com base, diretamente, na Constituição, a partir do critério de predominância do interesse, em função da extensão e intensidade dos impactos ambientais, e do princípio da subsidiariedade, em versão adaptada, segundo a qual, primariamente, as demandas deverão ser atendidas pela organização política mais próxima.

O Poder Judiciário aceita essa situação ou, pelo menos, não é do conhecimento deste expositor jurisprudência contrária ao exercício, pelo Município, da competência para o licenciamento de interesse local.

Situação mais clara é a da Resolução no 07/2005, do Conselho Nacional de Justiça (vedação do nepotismo no Poder Judiciário), cuja constitucionalidade foi afirmada, liminarmente, pelo Supremo Tribunal Federal, na $A D C$ no 12-MC/DF, com um voto divergente. Dessa Resolução disse o Ministro Carlos Britto, relator da $A D C$, que, "imediatamente inovadora do ordenamento jurídico", retirava "diretamente da Constituição o seu fundamento de validade, arrogando-se, portanto, a força de diploma normativo primário". O Ministro Eros Grau reafirmou seu ponto de vista doutrinário segundo o qual "a Constituição do Brasil consagra a legalidade como reserva da lei e como reserva da norma". Na segunda situação - reserva da norma - " "ainda quando as definições em pauta se operem em atos normativos não da espécie legislativa - mas decorrentes de previsão implícita ou explícita em lei - o princípio estará sendo devidamente acatado". Concluiu: "Já é tempo de afastarmos as concepções que os liberais do século XIX nutriam a respeito dos regulamentos, das quais muitos dos nossos publicistas ainda hoje fazem praça. A classificação das funções estatais segundo um critério material - função normativa, função jurisdicional e função administrativa - ainda não chegou aos ouvidos dessa gente, o que faz crer que não há ninguém 
mais conservador do que um liberal.... Dos demais votos favoráveis extrai-se, em resumo, que os princípios constitucionais podem e devem ser aplicados diretamente pela administração.

No julgamento do Ag. Reg. na Medida Cautelar na Reclamação no 6.702-5/PR, relator Ministro Ricardo Lewandowski, voltou o STF a afirmar que "a vedação do nepotismo não exige a edição de lei formal para coibir a prática, uma vez que decorre diretamente dos princípios contidos no art. 37, caput, da Constituição Federal".

$\mathrm{Na} 5^{\text {a }}$ Turma do Tribunal Regional Federal da $1^{\text {a }}$ Região, diferentemente da $6^{a}$ Turma, é afirmado que a ausência da lei prevista no art. $142, \S 3^{\circ}, X$, da Constituição (a lei disporá sobre o ingresso nas Forças Armadas, os limites de idade, a estabilidade e outras condições de transferência do militar para a inatividade ...) não significa a possibilidade de ingresso de pessoa de qualquer idade nas Forças Armadas. É esse - ausência de lei - um dos casos em que a administração pode e deve aplicar diretamente os princípios constitucionais. Não seria razoável que, admitida uma pessoa com idade avançada, viesse, com pouco tempo de serviço, a ser promovida ou a passar para a reserva remunerada em função da idade limite de permanência em determinado posto.

Concluo resumindo que a regulamentação autônoma está submetida aos requisitos - ouso improvisadamente estabelecer - de necessidade (cf. princípio dos poderes implícitos) e relevância, não pode invadir campo especificamente reservado à lei formal, mesmo na ausência desta, e não subsiste uma vez editada lei sobre a matéria.

\section{Limites à regulação julgadora}

Adverte Floriano Marques que uma "questão relevante sobre o controle dos poderes de conciliação diz respeito à hipótese de omissão do regulador no cumprimento dessa função. Afinal, a decisão dos conflitos no setor regulado pode, por vezes, ser encarada pelo regulador como um desgaste a ser evitado, levando-o a se esquivar de exercer seu papel de árbitro ou mediador. Parece, contudo, que, em se tratando de competência inerente à atividade de regulação estatal, qualquer omissão no seu exercício será afrontante ao princípio da função, que veda ao agente público furtar-se a exercer suas competências."10 Trata-se, pois, de limite negativo à regulação.

\footnotetext{
10 MARQUES NETO, Floriano de Azevedo. Agências reguladoras independentes: fundamentos e seu regime jurídico. Belo Horizonte: Fórum, 2005. p. 122-123.
} 
Ensaia-se no Tribunal Regional Federal da $1^{\text {a }}$ Região, por iniciativa deste expositor, discussão sobre tal limite negativo, o qual em algumas oportunidades deixou de ser obedecido pela Agência Nacional de Telecomunicações (ANATEL) quanto à disciplina das relações entre as empresas de telefonia no que diz respeito ao compartilhamento de redes e à interconexão.

Em relação à interconexão, previu a Lei no 9.472/97, art. 152, que seu provimento "será realizado em termos não discriminatórios, sob condições técnicas adequadas, garantindo preços isonômicos e justos, atendendo ao estritamente necessário à prestação do serviço". A omissão da ANATEL no estabelecimento de tal preço ensejou que empresas de telefonia ingressassem com ações destinadas a sua declaração diretamente pelo Poder Judiciário. Sustentou este expositor, em voto vencido, que ação correta, na hipótese, seria para que a ANATEL exercitasse sua competência, fixando o preço em referência, em vez de ação para que o juiz suprisse a omissão da entidade reguladora. Em outra ocasião, decidiu este expositor, monocraticamente, fixar prazo para que a ANATEL solucionasse conflito relacionado com o compartilhamento de redes, com os seguintes fundamentos:

A função administrativa é constituída pelas atividades-meio de todos os poderes ou funções do Estado e pelas atividades-fim do Poder Executivo, estas que incluem a intervenção na propriedade e no domínio econômico e social, a polícia e o serviço publico. A essas atividades-fim pode ser acrescentada a regulação.

Se a administração falha no exercício de suas atividades-fim - ex.: prestação do serviço de transporte coletivo de passageiros - o Poder Judiciário, em princípio, é chamado não para suprir a omissão, executando diretamente a atividade, mas para impor à administração o devido exercício de sua competência. Por isso, no caso, invariavelmente, a pessoa jurídica a que é atribuída a atividade deve figurar no pólo passivo da ação.

O exercício direto da atividade, pelo Poder Judiciário, só é possível acontecer, especialmente para preservar direitos fundamentais, em razão de previsível ineficácia de uma ordem à administração para que cumpra o dever de executar determinada tarefa (ex.: quando seja notório o desmantelo da administração naquele setor) e, ainda assim, somente enquanto permanece a omissão administrativa.

A conclusão desse raciocínio é que, em princípio (leia-se em primeira mão), não cabe ao Poder Judiciário prestar serviço público, exercer a polícia administrativa ou estabelecer ato regulatório. Caso concreto é o da pretensão manifestada, às vezes, pelo Ministério Público Federal (por meio de ação civil pública) de que o juiz interdite, diretamente (mediante ordem a ser cumprida por oficial 
de justiça), instituição de ensino, sob a alegação de que fora criada ou está funcionando ilegalmente. Há casos em que nem sequer é requerida citação da União, pessoa competente, por meio do Ministério da Educação, para o exercício da polícia administrativa nessa hipótese.

A mesma conclusão pode ser extraída em relação à atividade administrativa de regulação. Se a agência reguladora omite-se em sua atribuição de harmonizar os interesses de determinado setor, não cabe ao Poder Judiciário substituir aquela entidade em sua atribuição. A ação suscetível, em regra, de ser intentada nesse caso é para que o Poder Judiciário determine à agência reguladora que exercite sua competência. Depois de exercitada a competência - ex.: fixação dos preços de interconexão - as empresas poderão voltar ao Judiciário, mas com base em nova causa de pedir, para discutir a justiça da decisão administrativa.

No caso concreto, o Poder Judiciário não pode e nem é conveniente (uma vez que não dispõe imediatamente de condições técnicas), senão naquela situação excepcional, substituir a entidade reguladora, Agência Nacional de Telecomunicações, em sua competência, inclusive cautelar (cf. art. 45 da Lei n. 9.784/99), de disciplinar e policiar a convivência das empresas prestadoras do serviço de telefonia.

Penso que seriam esses os principais pontos a ressaltar dentro do tema que me foi atribuído.

Agradeço à professora Cristiana Fortini, Presidente do Instituto de Direito Administrativo de Minas Gerais, o convite para participar, em companhia de Alexandre - "o Grande", particularmente no tema tratado - deste notável seminário promovido em Uberlândia.

Limits to the Procedural Regulation, According to the Judiciary

Abstract: The procedural regulation consists in promoting the balance of political interests, interests of economic agents and public service providers, interests of consumers or users of goods and services and even the interests of people affected in their properties. Define the limits to this regulation, according to the Judiciary, in these three fields is the subject of this exhibition. Some cases are examined on the normative regulation and judicial regulation. The normative regulation is diveded into two items: a) executive regulation of legal texts and b) autonomous regulations without legal intermediation. Although the Administration can complement the criminal norm in blank, it cannot, according to legal precedents, criminalize violations and establish administrative penalties, creating taxes. The autonomic regulation is subject to the requirements of necessity and relevance, can not invade the field reserved for formal law, even in its absence, and disappears once edited a law on the specific matter. Legal precedents are starting to discuss the negative limit to the judgmental regulation.

Key words: Limit. Regulation. Normative. Judgment. 
Informação bibliográfica deste texto, conforme a NBR 6023:2002 da Associação Brasileira de Normas Técnicas (ABNT):

MOREIRA, João Batista Gomes. Limites à regulação, conforme o Poder Judiciário. A\&C

- Revista de Direito Administrativo \& Constitucional, Belo Horizonte, ano 10, n. 42, p. 87-97, out./dez. 2010.

Recebido em: 21.09.10

Aprovado em: 29.11 .10 